\title{
Customer Relationship Management Research in Tourism and Hospitality: A State-of-the-art
}

Purpose: This study aimed to provide a critical review of the evolution of customer relationship management $(\mathrm{CRM})$ research in the hospitality and tourism field.

Design/methodology/approach: The study conducted a thorough systematical literature review by collecting papers from 14 leading tourism and hospitality journals. The examination of the literature is first based on the evolution of CRM notion and its definitions. Next, CRM studies in the literature that are related to hospitality and tourism were assessed based on their timelines and themes. Thirdly, the studies were classified based on CRM components and its impacts on firms' performances.

Findings: The literature review provided an in-depth understanding on the progress of CRM based on the selected topics and suggests a redesigned research agenda for scholars, graduate students, and practitioners.

Implications: This study provides new and meaningful avenues for further research in CRM in hospitality and tourism area.

Originality/value: CRM has a key role in business performance and increased customer satisfaction and retention, specifically in the context of the service industry. To date, scholars have produced an abundant number of CRM related studies in tourism and hospitality journals. In this study, the progress of CRM research conducted in the tourism and hospitality sector is critically reviewed.

Keywords: Customer Relationship Management, Relationship Marketing, Hospitality, Tourism.

\section{Introduction}

Customer relationship management (CRM) is one of the successful marketing strategies that helps organizations increase their customer satisfaction, loyalty, and retention in order to build and manage long-term relationships (Bowen and Chen, 2001; Lo and Lee, 2010). Previous research has shown that CRM has been widely and successfully adopted by hospitality and tourism (H\&T) firms (Gilbert, 1996; Liu et al., 2000; Palmer et al., 2000). Additionally, scholars have studied different types of relationships within the field of CRM and the ways in which they impact and are integrated into organizations' structures. Recently, the CRM literature has grown due to the changes in the H\&T industry as well as the wants and needs of customers. The marketing, management, and information technology literature shows a number of studies that have demonstrated the evolution and state-of-the-art aspects of CRM (Boulding et al., 2005; 
Hennig-Thurau and Hansen, 2000; Hennig-Thurau et al., 2002; Malhotra and Kleiser, 1999; Sheth and Parvatiyar, 1995). Despite the growing interest of researchers in studying CRM, there is still very little research that focuses on evolution and state-of-the-art aspects of CRM in the H\&T field. Having identified this in the field, the main purpose of this study is to assess the progress of CRM. The paper proceeds as follows. We first examined the evolution of the definition of CRM. Next, CRM studies in the literature that are related to H\&T were assessed based on their timelines and themes. Thirdly, the studies were classified based on the three CRM components namely people, process and technology and CRM impacts on firms' performances. Finally, future research topics and methods are discussed.

\section{Methodology}

The critical review was conducted by focusing on the articles published in H\&T literature. Related articles were extracted from 14 leading H\&T journals, including Journal of Travel and Tourism Marketing, Annals of Tourism Research, International Journal of Hospitality Management, Journal of Hospitality Marketing and Management, Scandinavian Journal of Hospitality and Tourism Research, Journal of Hospitality and Tourism Research, Journal of Vacation Marketing, Journal of Travel Research, Cornell Hospitality Quarterly, Asian Pacific Journal of Tourism Research, Current Issues in Tourism, International Journal of Tourism Research, Anatolia: an International Journal of Tourism and Hospitality Research, and International Journal of Contemporary Hospitality Management. Main leading journals have been selected based on the impact factors of journals released by Journals of Citation Reports (2016). Other journals have been selected based on the reputation among the tourism and hospitality scholars and their contribution to the field. This scanning was conducted from September to November 2016. Our list of keywords was comprehensive and included a wide array of related terms including: Customer Relationship Marketing, Relationship Marketing, Datamining, Data Warehousing, Customer Satisfaction, Retention and Loyalty, Use of Technology, Upselling, Cross Selling, E-CRM, Buyer-Seller Relationships, and E-Commerce.

The website of each journal was used as the search platform. We searched for four aspects of selected papers to determine whether the document would qualify for our study: publication title, abstract, keywords, and reference identifiers (Samiee et al., 2015). As mentioned earlier we used three approaches to examine the progress of CRM within the H\&T literature. In our first approach, the papers were grouped based on their industry focus, themes and timelines: hospitality (29 papers) and tourism (10 papers). The second approach grouped papers based on the three components of CRM, namely People, Process Technology. The third approach focused on studies that have assessed the relationship between CRM and firms' performances. Finally, gaps related to three components and suggestions for future research were addressed. 


\section{Customer Relationship Management Notion}

Since the 1960s, the concept of marketing has been redefined by the emergence of several novel theories (Gilbert and Tsao, 2000). Under the general marketing field, relationship marketing $(\mathrm{RM})$ has received great attention as one of the new theories from both practitioners and scholars (Bennett, 1996; Gilbert, 1996; Gummesson, 1994; Kotler and Armstrong, 1996; Palmer, 1996). RM brought companies' attention into focusing on long-term goals and building long-term relationships with customers. By utilizing this approach, a company's focus switches from the value of the core product to creating more value for its customers. RM, with its customer-oriented approach, challenged the traditional marketing mix and its productionoriented approach (Gro Ėnroos, 1994; Rahimi and Gunlu, 2016). The use of the term "relationship" in conjunction with "marketing" denotes more than a connection with a buyer or supplier (i.e., a transaction-based exchange); however, RM lacks a unique definition, and numerous definitions are in use (Samiee et al., 2015).

Later this popular RM approach was replaced with a new approach called customer relationship marketing (CRM). RM has a strategic approach that focuses on empathy, reciprocity, and trust. However, its emotional and behavioral focus is considered to be limited. In return, CRM has a tactical approach and focuses on attracting, maintaining, and enhancing customer relationships, and is therefore more helpful as a business strategy (Sin et al., 2005; Yau et al., 2000). Although distinct from one another, the terms RM and CRM are often used interchangeably in the literature and in practice (Rahimi and Gunlu, 2016). However, there have been various attempts to define CRM as the reflection of the disciplinary approaches of marketing, management, and information technology. In this paper, we will use the term CRM to represent both RM and CRM.

Some scholars refer to CRM as a business philosophy (Ryals and Knox, 2001), some as a business strategy (Tarokh and Ghahremanloo, 2007), and others as a technological tool (Campbell, 2003). Others have used an integrated perspective from these three foci to form a coherent definition (Payne and Frow, 2005). Rababah et al. (2011, p. 223) combined these three perspectives as the building of a customer-oriented culture, by which a strategy is created for acquiring, enhancing the profitability of, and retaining customers. This is enabled by developments and advances of information-technology (IT) applications.

\section{Customer Relationship Management Research in Hospitality and Tourism}

In the context of service industries, CRM practices have been widely utilized to increase customer satisfaction and retention (Buttle, 2004; Pai and Tu, 2011). In H\&T managers are encouraged to adopt effective marketing strategies to attract more customers and retain the

existing ones. To facilitate this, CRM has received much attention from both scholars and practitioners (Cheng and Lam, 2008; Fyall et al., 2003; Josiassen et al., 2014; Rahimi and Gunlu, 
2016; Wang et al., 2012; $\mathrm{Wu}$ and $\mathrm{Lu}, 2012$ ). From the practical side, H\&T firms employ different CRM practices such as airlines' frequent flyer programs (Gilbert, 1996; Liu et al., 2000), hotel loyalty programs (Palmer at al., 2000), and car rental company customer preference schemes (Chadee and Mattsson, 1996). An examination of the academic literature reveals that there are a number of studies that have addressed different aspects of CRM concepts at various levels. Therefore, in the following section we address this progress at two levels of hospitalityrelated CRM literature and tourism-related CRM literature based on the distinguished themes and timelines.

\section{a. Hospitality-related CRM Literature and related Themes}

Technology - Initially, CRM was considered as software by different companies, and the role of organizational factors was neglected. Research utilized technology to examine the management of CRM (Cline, 1999). Later, the role of the Internet became more important for businesses to communicate with customers. This resulted in researchers shifting their focus to the way in which hotels utilize technology and multimedia information channels to build and create relationships with their customers (Gilbert and Powell-Perry, 2001). For example, Marinova et al. (2002) focused on the way Australian hotels utilized email marketing as a targeted promotion to build relationships with customers. Louvieris et al. (2003) considered the impact of Internet multi-channel access on the customer decision-making process, and the ways in which differences in buyer behavior and loyalty levels influence the RM process. They also considered the implications of effectively managing buyer behavior as well as the provision of multichannel customer accessibility for competitive advantage in hotels. Later, as the role of social media became critical for hotels, research has started focusing on the level of technology and Internet adoption for RM. Additionally, relationship between the level of online RM and hotel star rating, number of rooms, and locale of hotel web domains were studied (Gan et al., 2007). Murphy et al. (2003) focused on hotel websites and the quality of responses to customers' emails among 200 Swiss hotels. In another study, Raab et al. (2015) determined the impact of social media communication on hotels' loyalty programs.

Customer Satisfaction and Loyalty- Research has found that CRM can generate both tangible and intangible benefits for hotels (Rahimi et al., 2015). A significant number of studies in the hospitality-related literature have focused on the role and impact of CRM on customer satisfaction. Scanlan and McPhail (2000) found that hotel guests perceived personalization, social bonding, reliability, and familiarization to be the most influential factors in increasing their retention to the hotel. Focusing on luxury hotels in Korea, Kim et al. (2001) investigated the influence of relationship quality on the relationship consequences of commitment, repeat purchase, and word of mouth. Using hotel casinos, Sui and Baloglu (2003) developed and tested a model of loyalty to understand the positive behavioral outcomes of building relationships with local customers and the elements that contribute to these behavioral outcomes. Tideswell and 
Fredline (2004) evaluated the effectiveness of the marketing strategies used to create guest loyalty in hotels by asking guests their point of view.

Hyun (2010) investigated which factors influenced relationship quality, customer loyalty formation, and the connection between relationship quality and loyalty in restaurants. Focusing on the hotel industry, $\mathrm{Wu}$ and $\mathrm{Lu}$ (2011) investigated the relationship among CRM, relationship quality, and customer value from the consumer's perspective. In their study, Swimberghe and Wooldridge (2014) explored the effect of customers' perceptions of Chick-fil-A's food, service, environment, and corporate social responsibility based on customer satisfaction, trust, and identification with the restaurant. Maier and Prusty (2015) provided new insights into customer behavioral patterns associated with RM practices in private clubs, providing club managers with practical ways to improve member retention strategies. Rahimi and Kozak (2016) explained the impact of CRM on customer satisfaction in a UK budget hotel.

Firms' Performances - CRM cannot only increase customer satisfaction and retention, but it can also have a significant impact on a firm's performance. Piccoli et al. (2003) focused on CRM as a driver for change in the structure of the U.S. lodging industry. Looking at the impact on the performance of the businesses, Kim et al. (2006) examined the relationships among elements of RM activities (predictors), relationship quality (a mediating construct), and relationship outcomes (commitment, loyalty, and word of mouth). The study by Sin et al. (2006) collected data from 63 hotels in Hong Kong and found that RM orientation was positively and significantly associated with marketing performance and financial performance. Prentice and King (2011) investigated the effectiveness of customer orientation and adaptability approaches and the ways they influence the performance of frontline employees.

Wang (2012) examined the compatibility between CRM and revenue management in hotels, and discussed possible management conflicts that occur from both account managers' and revenue managers' viewpoints. Prentice and King (2011), using the VIP gaming areas of one of the world's largest casinos, investigated the effectiveness of customer orientation and adaptability approaches and the ways in which they influence the performance of frontline employees. Wu and $\mathrm{Lu}$ (2012) investigated the implementation of CRM in the hotel industry in Taiwan and its effect on RM and business performance. Chen and Chen (2014) studied the hotel industry in Taiwan and investigated the effect of RM on corporate image and service quality, and the interrelation between corporate image and service quality. Josiassena et al. (2014) examined the influence of each CRM dimension on hotels' performances.

Looking at CRM Implementation, Sigala (2005) proposed a model for managing and integrating information and communication technology (ICT) capabilities into hotels' CRM strategies and business processes. Rahimi and Gunlu (2016) investigated the impact of organizational culture factors on implementing CRM strategies in hotels, and further tried to adapt the Mendoza et al. (2007) CRM model to the hotel context. Padilla-Meléndez and Garrido- 
Moreno (2014) analyzed the main CRM implementation success factors based on a sample of 128 small and medium-sized hotels in Spain. Rachel and Hu (2008) developed a research framework incorporating various technical, organizational, and environmental factors that influence the adoption of electronic CRM (e-CRM) systems. Their findings show that these approaches are significant predictors of service performance.

\section{b. Tourism-related CRM Literature and related Themes}

There are several studies elucidating CRM issues in the tourism industry.

Destination Management - Fyall et al. (2003) focused on Stockholm and Barbados, and analyzed the degree of RM implementation in these destinations. They also explored the opportunities and challenges faced by managers of the destinations in their attempt to engender loyalty and repeat visitations. Peters (2004) examined ways the Winnebago Itasca Travelers (WIT) Club in the USA attracts new customers and builds customer loyalty by using vocabularies of motives and core framing activities. Pike et al. (2011) pulled from the wider marketing literature and a prior qualitative study to develop a CRM model and a scale to operationalize destination marketing organization (DMO) visitor relationship orientation. Choo and Petrick (2012) examined the effects of different relationships on visitors' tourism experiences at agritourist encounters, recognizing the differences between repeaters and firsttimers from an RM perspective.

Firms' Performances and Customer Satisfaction - Another set of studies focused on the CRM impact on the performance of travel agencies, tour operators, and their customers. In their work, Álvarez et al. (2007) examined the impact of the Internet on the management of existing relationships between retail travel agencies and their customers. They also determined the opportunities travel agencies offer customers, as well as investigated its influence on trust (one of the key variables in RM). Conze et al. (2010) focused on the benefits of RM for customers in the travel industry and investigated the effects among relational benefits, relationship intention, and intentional loyalty of the tour operator industry. Tsaur et al. (2014) focused on the relationship between blog function characteristics and RM outcomes, and clarified the effects of tour leaders' charisma. Yen at al. (2015) focused on the effects of customers' relational benefits on RM outcomes in the travel industry. Whyte (2003) studied Australian airlines' frequent flyer programs and examined the concept of RM. Their findings show that the schemes create spurious loyalty and that the issue of loyalty is much broader than merely accepting repeat purchase as a proxy for consumer satisfaction. Other studies have focused on the various aspects of CRM on the travel industry. Stockdale (2007) examined the concepts of e-CRM and selfservice technologies (SSTs) within the travel and tourism industries. The study considered the ways SSTs can be complemented by effective e-CRM strategies, and identified the essential constructs of those strategies for customer relationship building within the industry. 
Linkage with the Culture- Several other previous studies have attempted to link the cultural side of societies with CRM, in particular, the Chinese Guanxi culture (Geddie et al., 2002; Tesao, 2000). For example, Geddie et al. (2002) looked into the history and development of Guanxi in China and its similarities to CRM in the Western world. These authors also explored the ways that the constructs of Guanxi can be combined with CRM. Hu et al. (2005) investigated the ways e-CRM theories can be applied to the websites of selected postsecondary H\&T programs in the United States. McCall and Voorhees (2010) focused on the factors that drive a successful loyalty program. As the above review demonstrates, the CRM concept is wellresearched from the hospitality side, but it remains relatively untested for the other aspects of tourism.

\section{CRM Studies in H\&T Based on the Components}

Successful CRM implementation needs a holistic approach by considering people, process, and technology (Bull, 2003; Chen and Popvich, 2003; Mendoza et al., 2006; Rahimi, 2017a; Rahimi and Gunlu, 2016; Zablah et al., 2004). The technology component helps implement CRM by collecting and analyzing data on customers' patterns and behavior, as well as developing predictive models. Initially, the technology component was considered a piece of software that companies could use to collect and analyze customer data as a foundation for database marketing (Callan and Teasdale, 1999; Cline, 1999; Law et al., 2014; Rahimi et al., 2017; Hassan and Rahimi, 2016). For example, Sigala (2005) proposed a model for managing and integrating ICT capabilities into CRM strategies and business processes in hotels. The roles of the Internet and social media have altered this approach. The majority of recent studies have focused on the role of technology and different aspects of it, including the role of web presence (Powell-Perry, 2001), level of Internet adoption (Gan et al., 2007), use of a website and email (Álvarez et al., 2007; Murphy et al., 2003), impact of Internet multi-channel access on the customer decision-making process (Louvieris et al., 2003), e-CRM, self-service (Stockdale, 2007), and the use of social media (Raab et al., 2015).

Over the last 30 years, progress of ICTs, establishments of the Computer Reservation Systems (CRSs), and Global Distribution Systems (GDSs) has transformed operational and strategic practices dramatically in the H\&T industry (Buhalis, 2003; Buhalis and Law, 2008; Buhalis and Jun, 2011). As a result of this progress, e-tourism and e-commerce has evolved and impacted the way CRM works and is implemented in different organizations. For example, Buhalis (2003) suggested that e-tourism reflects the digitization of all processes and value chains in the tourism, travel, hospitality, and catering industries. At the tactical level, this includes utilizing e-commerce and applying ICTs in order to maximize the efficiency and effectiveness of the tourism organization. Hence many organizations are forced to consider adopting the concept of e-CRM. E-CRM expands the traditional CRM techniques by integrating technologies of new electronic channels, such as Web, wireless, and voice technologies, and combines them with ebusiness applications into the overall enterprise CRM strategy (Pan and Lee, 2003). E-CRM 
enables companies to collect, organize, and disseminate a wealth of customer information, ultimately providing valuable one-to-one relationships with customers.

The CRM process component attempts to shift the direction of the firm toward a customer-centric approach by focusing on internal and external processes. A review of the literature suggests that there is limited number of studies focusing on the process component of CRM and the required organizational changes (Rahimi, 2017b; Rahimi and Gunlu, 2016). While Rahimi and Gunlu (2016) focused on the required organizational culture changes, other necessary aspects have been widely neglected in the literature. The people component includes organizational readiness and collaboration with staff as an essential factor for successful CRM implementation (Chakravorti, 2006; Rahimi, 2017b). The people component plays a key role in the success of CRM strategies (Chen and Popvich, 2003). However, the role, performance, and influence of staff on implementing CRM in the context of H\&T have not been extensively investigated (Prentice and King, 2011). Some studies have taken a balanced approach and focused equally on all three components. For example, Racherla and Hu (2008) developed a research framework that incorporated various technical, organizational, and environmental factors that influence the hospitality organizations' adoption of e-CRM systems. PadillaMeléndez and Garrido-Moreno (2014) studied and analyzed the main success factors of CRM implementation in hotels.

Researchers have also expended much scholarly effort to investigate the impact of CRM implementation on a firm's performance ( $\mathrm{Wu}$ and $\mathrm{Lu}, 2012$ ), revenue management (Wang, 2012), corporate image and service quality (Chen and Chen, 2014), marketing, and financial performance (Sin et al., 2006), customers' satisfaction (Conze et al., 2010; Rahimi and Kozak, 2016), customer loyalty (Hyun, 2010; Peters, 2004; Tideswell and Fredline, 2004; Whyte, 2003), commitment, satisfaction, trust, repeat purchase, word of mouth (Kim et al., 2001; Kim et al., 2006; Swimberghe and Wooldridge, 2014), or using customer behavioral patterns in RM (Maier and Prusty, 2015). To discuss the progress in H\&T literature we used balance scorecards (Kaplan and Norton, 1992) including five components - financial perspectives, internal business perspective, innovation and learning perspective, customer perspective, and strategy (Figure 1). 


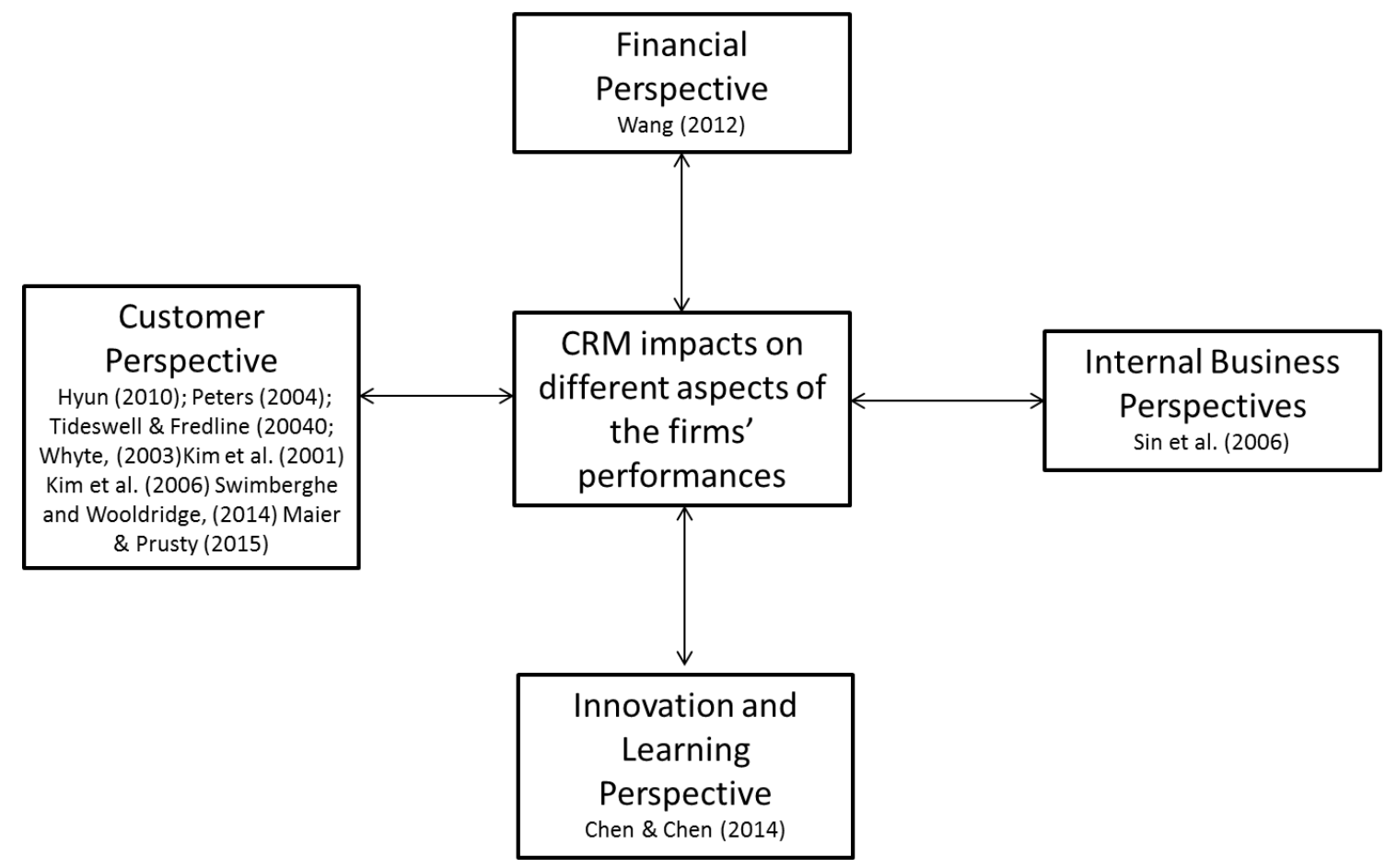

Figure 1-Studies on relationship between CRM and firms' performances

\section{Conclusions and Future Research}

This study aimed to provide a critical review of the evolution of CRM research in the H\&T field. Based on this critical review, several conclusions can be provided on how CRM research has evolved, key research topics, authors and research methods. CRM research in the H\&T field shows that CRM is not yet a well-researched topic, specifically on the tourism side. The majority of published research articles are in the area of hospitality, with a specific focus on hotels and restaurants. Therefore, more studies with a focus on pubs and clubs are required. Future research in the tourism area, especially at the destination level is also required. Future studies are also needed to expand the horizon of research to a multi-destination approach and tourists' behaviors.

With global competition and newly emerging destinations, tourists have become more sophisticated in their choices. In this regard, CRM including three components - people, technology and process- as the building of a customer-oriented culture, by which a strategy is created for acquiring, enhancing the profitability of, and retaining customers (Rababah et al., 2011) can be used by companies in the H\&T industry to achieve a competitive advantage. Previous studies both utilized qualitative and quantitate research methods but mostly relied on a single data collection method. Future studies may follow a longitudinal research design and utilize multiple data collection methods. Majority of previous CRM studies were undertaken in 
western and developed countries. It is suggested that future studies should look into CRM practices in Asian and developing countries.

Future studies should collect data from small and medium H\&T organizations as well as large corporations. In examining the three components of CRM, the technology aspect has received the most attention while the roles of people and process have been widely neglected. There is a need for an innovative approach to look at big data in examining CRM. While it is evident that CRM brings many tangible and intangible benefits to companies, more studies are needed to explore the customer side of the relationship. These studies can address whether CRM contributes to customer satisfaction and which aspects of CRM are perceived by customers to be satisfying. The topic of e-CRM is widely researched in the marketing, management, and information technology fields. However, there is a need for H\&T scholars to focus on e-CRM. There is also a significant gap in the literature on the relationship CRM plays in practices and performances of companies. More studies on the revenue management, financial performance, internal business, and innovation and learning specifically in the tourism domain are required. Hence, future research studies should address the following issues:

- How do CRM practices affect the financial performance of firms?

- Is there any relationship between CRM and revenue management? If yes, what aspects should managers focus on?

- Is there a relationship between CRM and the internal performance of firms? If yes, how are CRM practices integrated into internal processes?

- How does CRM impact a firm's innovation performance?

- How is the performance of CRM practices currently measured?

Finally, no previous study in has critically reviewed CRM literature in the H\&T field via bibliometric analysis (Koseoglu et al., 2016). Given this, a bibliometric study can be undertaken to

a) Identify the growth and changes of research related to CRM in the H\&T field over time;

b) categorize the leading authors and the degree of multiple authorships in articles by journal categories and years;

c) Identify institutional contributions based on their locations in either developed or developing countries;

d) Identify how related subjects evolved over time in the articles based on tourism or hospitality streams;

e) Categorize the methodology changes over time; and, finally, suggest a future research agenda. 


\section{References}

Álvarez, L. S., Martín, A. M. D., \& Casielles, R. V. (2007). Relationship marketing and information and communication technologies: Analysis of retail travel agencies. Journal of Travel Research, 45(4), 453-463.

Bennett, R. (1996). Relationship formation and governance in consumer markets: Transactional analysis versus the behaviourist approach. journal of Marketing Management, 12(5), 417-436.

Boulding, W., Staelin, R., Ehret, M., \& Johnston, W. J. (2005). A customer relationship management roadmap: What is known, potential pitfalls, and where to go. Journal of Marketing, 69(4), 155-166.

Buhalis, D. (2003). eTourism: Information Technology for Strategic Tourism Management. London, UK: Pearson (Financial Times/Prentice Hall).

Buhalis, D., \& Jun, S. H. (2011). E-tourism. Contemporary Tourism Reviews, 2-38.

Buhalis, D., \& Law, R. (2008). Progress in information technology and tourism management: 20 years on and 10 years after the Internet - The state of eTourism research. Tourism Management, 29(4), 609-623.

Buttle, F. (2009). Customer relationship management: Concepts and technologies. Routledge.

Callan, R. J., \& Teasdale, A. (1999). Hotel guest history as the foundation for database marketing: Embracing a pilot survey of UK hotels. Journal of Vacation Marketing, 5(2), 140153.

Campbell, A. J. (2003). Creating customer knowledge competence: Managing customer relationship management programs strategically. Industrial Marketing Management, 32(5), 375383.

Chao, C., Jen, W., Chi, Y., \& Lin, B. (2007). Determining technology trends and forecasts of CRM through a historical review and bibliometric analysis of data from 1991 to 2005. International Journal of Management and Enterprise Development, 4(4), 415-427.

Chen, W. J., \& Chen, M. L. (2014). Factors affecting the hotel's service quality: Relationship marketing and corporate image. Journal of Hospitality Marketing \& Management, 23(1), 77-96.

Choo, H., \& Petrick, J. F. (2012). Comparison between first-timers and repeaters for relationship marketing implications. International Journal of Tourism Research, 14(3), 298-302. 
Cline, R. S. (1999). Hospitality 2000-the technology: Building customer relationships. Journal of Vacation Marketing, 5(4), 376-386.

Conze, O., Bieger, T., Laesser, C., \& Riklin, T. (2010). Relationship intention as a mediator between relational benefits and customer loyalty in the tour operator industry. Journal of Travel \& Tourism Marketing, 27(1), 51-62.

Fetscherin, M., \& Heinrich, D. (2015). Consumer brand relationships research: A bibliometric citation meta-analysis. Journal of Business Research, 68(2), 380-390.

Foss, B., Stone, M., \& Ekinci, Y. (2008). What makes for CRM system success-Or failure?. Journal of Database Marketing \& Customer Strategy Management, 15(2), 68-78.

Fyall, A., Callod, C., \& Edwards, B. (2003). Relationship marketing: The challenge for destinations. Annals of tourism research, 30(3), 644-659.

Gan, L., Sim, C. J., Tan, H. L., \& Tna, J. (2007). Online relationship marketing by Singapore hotel websites. Journal of Travel \& Tourism Marketing, 20(3-4), 1-19.

Geddie, M. W., DeFranco, A. L., \& Geddie, M. F. (2002). From Guanxi to customer relationship marketing: How the constructs of Guanxi can strengthen CRM in the hospitality industry. Journal of Travel \& Tourism Marketing, 13(3), 19-33.

Gilbert, D. C. (1996). Relationship marketing and airline loyalty schemes. Tourism Management, $17(8), 575-582$.

Gilbert, D., \& Powell-Perry, J. (2001). Exploring developments in web based relationship marketing within the hotel industry. Journal of Hospitality \& Leisure Marketing, 9(3-4), 141159.

Gilbert, D., \& Tsao, J. (2000). Exploring Chinese cultural influences and hospitality marketing relationships. International Journal of Contemporary Hospitality Management, 12(1), 45-54.

Gro Ènroos, C. (1994). From marketing mix to relationship marketing. Journal of Academic Marketing Science, 23(4), 252 -254.

Gummesson, E. (1994). Relationship marketing: Its role in the service economy.

Gummesson, E. (2011). Total relationship marketing. Routledge.

Hassan, A., \& Rahimi, R. (2016). Consuming "Innovation" in Tourism: Augmented Reality as an Innovation. Global Dynamics in Travel, Tourism, and Hospitality, 130. 
Hennig-Thurau, T., \& Hansen, U. (2000). Relationship marketing - some reflections on the state-of-the-art of the relational concept. In Relationship Marketing (pp. 3-27). Springer Berlin Heidelberg.

Hennig-Thurau, T., Gwinner, K. P., \& Gremler, D. D. (2002). Understanding relationship marketing outcomes an integration of relational benefits and relationship quality. Journal of Service Research, 4(3), 230-247.

Hu, C., Jang, S. S., \& Bai, B. (2005). E-relational characteristics on hospitality and tourism program web sites. Journal of Hospitality \& Tourism Research, 29(4), 508-522.

Hyun, S. S. (2010). Predictors of relationship quality and loyalty in the chain restaurant industry. Cornell Hospitality Quarterly, 51(2), 251-267.

Kaplan, R. S., \& Norton, D. P. (1992). The balanced scorecard: Measures that drive performance. Harvard Business Review, 70(1), 61-66.

Kim, W. G., Han, J. S., \& Lee, E. (2001). Effects of relationship marketing on repeat purchase and word of mouth. Journal of Hospitality \& Tourism Research, 25(3), 272-288.

Koseoglu. M, Rahimi. R, Okumus. F, Liu. J (2016). Bibliometric Studies in Tourism. Annals of Tourism Research. DOI: 10.1016/j.annals.2016.10.006.

Kotler, P., \& Armstrong, G. (1996). Principles of marketing. Mercadotecnia (No. 658.8 K87mE 1996). Prentice Hall.

Lee, S., Su, H. J., \& Dubinsky, A. J. (2005). Relationship selling in the meeting planner/hotel salesperson dyad. Journal of Hospitality \& Tourism Research, 29(4), 427-447.

Li, C., \& Ke, J. (2009, January). Bibliometric analysis of data mining in the Chinese Social Science Circle. In Knowledge Discovery and Data Mining, 2009. WKDD 2009. Second International Workshop on (pp. 231-234). IEEE.

Louvieris, P., Driver, J., \& Powell-Perry, J. (2003). Managing customer behaviour dynamics in the multi-channel e-business environment: Enhancing customer relationship capital in the global hotel industry. Journal of Vacation Marketing, 9(2), 164-173.

Maier, T. A., \& Prusty, S. (2015). Managing customer retention in private clubs using churn analysis: Some empirical findings. Journal of Hospitality Marketing \& Management, 1-23. 
Malhotra, N. K., Peterson, M., \& Kleiser, S. B. (1999). Marketing research: A state-of-the-art review and directions for the twenty-first century. Journal of the Academy of Marketing Science, 27(2), 160-183.

Marinova, A., Murphy, J., \& Massey, B. L. (2002). Permission E-mail marketing as a means of targeted promotion. Cornell Hotel and Restaurant Administration Quarterly, 43(1), 61-69.

McCall, M., \& Voorhees, C. (2010). The drivers of loyalty program success an organizing framework and research agenda. Cornell Hospitality Quarterly, 51(1), 35-52.

Mendoza, L. E., Marius, A., Pérez, M., \& Grimán, A. C. (2007). Critical success factors for a customer relationship management strategy. Information and Software Technology, 49(8), 913945

Murphy, J., Olaru, D., Schegg, R., \& Frey, S. (2003). Swiss hotels' web-site and e-mail management the bandwagon effect. Cornell Hospitality Quarterly, 44(1), 71-87.

Padilla-Meléndez, A., \& Garrido-Moreno, A. (2014). Customer relationship management in hotels: Examining critical success factors. Current Issues in Tourism, 17(5), 387-396.

Pai, J. C., \& Tu, F. M. (2011). The acceptance and use of customer relationship management (CRM) systems: An empirical study of distribution service industry in Taiwan. Expert Systems with Applications, 38(1), 579-584.

Palmer, A. J. (1996). Relationship marketing: a universal paradigm or management fad?. The Learning Organization, 3(3), 18-25.

Pan, S. L., \& Lee, J. N. (2003). Using e-CRM for a unified view of the customer. Communications of the ACM, 46(4), 95-99.

Payne, A., \& Frow, P. (2005). A strategic framework for customer relationship management. Journal of Marketing, 69(4), 167-176.

Pedron, C. D., \& Saccol, A. Z. (2009). What lies behind the concept of customer relationship management? Discussing the essence of CRM through a phenomenological approach. BARBrazilian Administration Review, 6(1), 34-49.

Peters, C. L. O. (2004). Using vocabularies of motives to facilitate relationship marketing: the context of the Winnebago Itasca Travelers Club. Journal of Vacation Marketing, 10(3), 209-222. 
Piccoli, G., O'Connor, P., Capaccioli, C., \& Alvarez, R. (2003). Customer relationship management-a driver for change in the structure of the US lodging industry. Cornell Hospitality Quarterly, 44(4), 61.

Pike, S., Murdy, S., \& Lings, I. (2011). Visitor relationship orientation of destination marketing organizations. Journal of Travel Research, 50(4), 443-453.

Prentice, C., \& King, B. (2011). Relationship marketing in the casino industry. Journal of Vacation Marketing, 17(1), 51-63.

Raab, C., Berezan, O., Krishen, A. S., \& Tanford, S. (2015). What's in a word? Building program loyalty through social media communication. Cornell Hospitality Quarterly, 57(2), 138149.

Rababah, K., Mohd, H., \& Ibrahim, H. (2011). A unified definition of CRM towards the successful adoption and implementation. Academic Research International, 1(1), 220.

Racherla, P., \& Hu, C. (2008). eCRM system adoption by hospitality organizations: A technology-organization-environment (TOE) framework. Journal of Hospitality \& Leisure Marketing, 17(1-2), 30-58.

Rahimi, R. (2017a). Customer relationship management (people, process and technology) and organizational culture in hotels: Which traits matter? International Journal of Contemporary Hospitality Management, 29(5). DOI: 10.1108/IJCHM-10-2015-0617.

Rahimi, R. (2017b). Organizational culture and customer relationship management: A simple linear regression analysis. Journal of Hospitality Marketing \& Management. DOI: 10.1080/19368623.2017.1254579.

Rahimi, R., \& Gunlu, E. (2016). Implementing customer relationship management (CRM) in hotel industry from organizational culture perspective: Case of a chain hotel in the UK. International Journal of Contemporary Hospitality Management, 28(1), 89-112.

Rahimi, R., \& Kozak, M. (2016). Impact of customer relationship management on customer satisfaction: The case of a budget hotel chain. Journal of Travel \& Tourism Marketing, 1-12.

Rahimi, R., Hassan, A., \& Tekin, O. (2017). Augmented reality apps for tourism destination promotion. In Apps Management and E-Commerce Transactions in Real-Time. pp. 236-251. IGI Global. 
Rahimi, R., Nadda, V. and Wang, H. (2015). CRM in Tourism. In: R. Nilanjan, ed., Emerging Innovative Marketing Strategies in the Tourism Industry, 1st ed. Pennsylvania: IGI Global, pp.16-43.

Ryals, L., \& Knox, S. (2001). Cross-functional issues in the implementation of relationship marketing through customer relationship management. European Management Journal, 19(5), 534-542.

Samiee, S., Chabowski, B. R., \& Hult, G. T. M. (2015). International relationship marketing: Intellectual foundations and avenues for further research. Journal of International Marketing, 23(4), 1-21.

Scanlan, L., \& McPhail, J. (2000). Forming service relationships with hotel business travelers: The critical attributes to improve retention. Journal of Hospitality \& Tourism Research, 24(4), 491-513.

Shani, D., \& Sujana,C. (1992). Exploiting niches using relationship marketing. Journal of Consumer Marketing ,9(3), 33-42.

Sheth, J. N., \& Parvatiyar, A. (1995). The evolution of relationship marketing. International Business Review, 4(4), 397-418.

Sin, L. Y. M., Tse, A. C. B., Heung, V. C. S., \& Yim, F. H. K. (2006). The effects of relationship marketing orientation on business performance in the hotel industry. Journal of Hospitality \& Tourism Research, 30(4), 407-426.

Sin, L. Y., Alan, C. B., Yau, O. H., Chow, R. P., Lee, J. S., \& Lau, L. B. (2005). Relationship marketing orientation: Scale development and cross-cultural validation. Journal of Business Research, 58(2), 185-194.

Stockdale, R. (2007). Managing customer relationships in the self-service environment of etourism. Journal of Vacation Marketing, 13(3), 205-219.

Sui, J. J., \& Baloglu, S. (2003). The role of emotional commitment in relationship marketing: An empirical investigation of a loyalty model for casinos. Journal of Hospitality and Tourism Research, 27(4), 470-489.

Swimberghe, K. R., \& Wooldridge, B. R. (2014). Drivers of customer relationships in quickservice restaurants The role of corporate social responsibility. Cornell Hospitality Quarterly, 111. 
Tarokh, M. J., \& Ghahremanloo, H. (2007, August). Intelligence CRM: A contact center model. In Service Operations and Logistics, and Informatics, 2007. SOLI 2007. IEEE International Conference on (pp. 1-6). IEEE.

Tideswell, C., \& Fredline, E. (2004). Developing and rewarding loyalty to hotels: The guest's perspective. Journal of Hospitality \& Tourism Research, 28(2), 186-208.

Tsaur, S. H., Wu, D. H., Yen, C. H., \& Wu, M. H. (2014). Promoting relationship marketing of tour leaders' blog: The role of charisma. International Journal of Tourism Research, 16(5), 417428.

Whyte, R. (2003). Loyalty marketing and frequent flyer programmes: Attitudes and attributes of corporate travellers. Journal of Vacation Marketing, 9(1), 17-34.

Yau, O. H., Lee, J. S., Chow, R. P., Sin, L. Y., \& Alan, C. B. (2000). Relationship marketing the Chinese way. Business Horizons, 43(1), 16-24.

Yen, C. H., Liu, L. L., Chen, C. Y., \& Lee, T. Y. (2015). Customer relational benefits and relationship-marketing outcomes: Comparing three transaction types of travel product. Asia Pacific Journal of Tourism Research, 20(2), 171-190. 